\title{
Morphological Spectrum of Lesions in Upper Gastrointestinal Endoscopic Biopsies
}

\author{
Janani Mathialagan ${ }^{1}$, Bhavani K ${ }^{1 *}$, Sowmya S ${ }^{1}$, Tirou Aroul ${ }^{2}$ and Sajeeth Manikanda Prabu ${ }^{3}$ \\ 'Dept of Pathology, Mahatma Gandhi Medical College and Research Institute, Sri Balaji Vidyapeeth Deemed to be \\ University Puducherry, India -607402 \\ ${ }^{2}$ Dept of General Surgery, Mahatma Gandhi Medical College and Research Institute, Puducherry, Sri Balaji Vidyapeeth \\ Deemed to be University India-607402 \\ ${ }^{3}$ Dept of Medical Gastroenterology, Mahatma Gandhi Medical College and Research Institute, Puducherry, \\ Sri Balaji Vidyapeeth Deemed to be University India-607402
}

\section{ABSTRACT}

Background: Gastrointestinal disorders are one of the most common clinically encountered problem. The Spectrum varies significantly due to geographical, dietary and environmental factors. Endoscopic examination along with histopathological biopsy examination is the gold standard for the detection of lesions. Correlation with other clinical data aids in accurate and early diagnosis of lesions.

Methods: This descriptive study comprises of 454 endoscopic biopsies of gastrointestinal tract received in the Department of Pathology, Mahatma Gandhi Medical College and Research Institute, Pondicherry over a period of 18 months from December 2016 to May 2018. Brief clinical data, provisional clinical diagnosis, endoscopic findings and histopathological diagnosis were noted.

Result: Of the 454 cases examined, $53.9 \%$ of patients were males. Highest incidence was recorded in the $41-50$ age group comprising of $22.4 \%$. Endoscopic examination showed maximum cases with inflamed mucosa (38.5\%). The commonest biopsied site is Gastric antrum. Non-neoplastic lesions were more prevalent (83.4\%) than neoplastic lesions.

Conclusion: Histopathological evaluation along with details of endoscopic findings aids in providing an accurate diagnosis.

\section{Keywords: Biopsy, Endoscopy, Histopathology, Upper Gastrointestinal Tract.}

\section{Introduction}

Gastrointestinal disorders are one of the most commonly encountered health problems in routine clinical practice. Dietary, environmental, geographic and genetic factors are some of the key reasons contributing to the prevalence of this condition ${ }^{[1]}$. The lesions can range from infectious diseases which can be treated medically to malignant lesions requiring surgical and chemotherapeutic approach $^{[2]}$. Open-access endoscopy is a safe and reliable procedure for both visualization and sampling of specific areas in the gastrointestinal tract ${ }^{[3]}$.

This present study was undertaken to analyze the spectrum of lesions of the upper gastrointestinal tract by endoscopic biopsies along with simultaneous evaluation of clinical data and endoscopic findings reported in the Department of Pathology in Mahatma Gandhi Medical College and Research Institute, Sri Balaji Vidyapeeth Deemed to be University, Puducherry and to determine the role of histopathology in concluding at a final diagnosis and to perform clinico-pathological correlation.

\section{Materials and Methods}

This descriptive study was conducted in Mahatma Gandhi Medical College and Research Institute in Pondicherry. The present study comprises of upper gastrointestinal endoscopic biopsy specimens received from December 2016 to May 2018. The Institutional Human Ethics Committee approved this study. The specimens were analyzed with reference to clinical findings, endoscopic findings and histopathological diagnosis. Four hundred and fifty four samples were received during this period.

\section{Procedure}

Samples are received in the histopathology lab and are processed and embedded in paraffin blocks. Sections from the blocks were stained with hematoxylin and eosin and examined under light microscope. Depending upon the $\mathrm{H}$ \& E histomorphology, special stains such as Giemsa for Helicobacter pylori and Periodic Acid Schiff for fungal elements were applied to demonstrate the micro-organisms. All the staining procedures were done as per the procedures and guidelines given in Bancroft and Gamble $e^{[4]}$.

Microscopic examination was done and lesions were classified broadly into Non-neoplastic (inflammatory and infective) and Neoplastic (benign and malignant). Clinicopathological correlation was done based on clinical details, endoscopic findings and histopathological diagnosis. Findings were analysed and compared with literature.

\section{Inclusion criteria}

- Endoscopic biopsies of lesions from upper GIT. 


\section{Exclusion criteria}

- Biopsies from oral cavity and pharynx

- All biopsies below second part of duodenum

\section{Result}

Four hundred and fifty four specimens of upper gastrointestinal endoscopic biopsies were studied over a period of 18 months from December 2016 to May 2018 in the Department of Pathology, MGMCRI, Sri Balaji Vidyapeeth Deemed to be University Pondicherry and the following observations were made.

Majority of patients were males accounting for 53.9\% and the rest were all females. The male: female ratio is 1.17:1.

The youngest patient was 3yrs old and the oldest patient was $90 \mathrm{yrs}$ old. The majority of patients were between the age group of 41-50 years accounting for $22.4 \%$.

Dysphagia and dyspepsia are the most prevalent clinical presentation finding. On endoscopic examination, inflamed mucosa was the most common finding seen in 175 cases $(38.5 \%)$ as shown in table 1 .

The most commonly sampled biopsy site is stomach which constituted of about 379 cases (84\%) followed by duodenum which had 36 cases $(8 \%)$ as shown in table 2. With regard to biopsy sampled from stomach, gastric antrum is the highest sampled area $(60 \%)$ followed by fundus $(22 \%)$, body $(15 \%)$ and pylorus $(3 \%)$.

Non-neoplastic lesions constituted the majority of the studied cases of $379(83.4 \%)$ followed by neoplastic lesions which accounted for only 75 cases (16.6\%).
Among 379 non-neoplastic lesions, 284 cases $(75 \%)$ are inflammatory in nature and infective lesions were only 95 cases $(25 \%)$.

Among the 95 infective cases reported, 94 cases of H.pyloric gastritis and only one case of oesophageal candidiasis was observed as shown in table 3.

Among the 284 inflammatory lesions, 237 cases were reported as chronic gastritis which constituted of about $83.4 \%$

Among 75 neoplastic lesions, malignant lesions were 70 cases $(93 \%)$ and benign lesions were only 5 cases $(7 \%)$ as shown in table 4.

Among the 5 benign lesions encountered, hyperplastic polyp and benign carcinoid tumour were equal in proportion with 2 cases each, accounting for $80 \%$ together. One case of gastric adenoma was also reported.

Among the 70 malignant lesions, 44 cases of adenocarcinoma which accounted for about $63 \%$ and 23 cases of squamous cell carcinoma which accounted for about $33 \%$ were reported.

Clinico-histopathological concordance was observed in $80 \%$ of cases and discordance was observed in $20 \%$ of cases as shown in table 5 .

Among malignant lesions, clinico-pathological correlation was observed in $50 \%$ of cases. None of the benign lesions showed any clinicopathological correlation as shown in table 6 .

Among inflammatory lesions, clinico-pathological correlation was observed in $84 \%$ of cases. Infective lesions showed $98 \%$ clinicopathological correlation as shown in table 7.

Table 1: Patterns of endoscopic findings in upper GIT.

\begin{tabular}{|c|c|c|}
\hline Endoscopic findings & No of cases & Percentage \\
\hline Inflamed mucosa & 175 & 38.5 \\
\hline Patches & 114 & 25.5 \\
\hline Ulceration & 100 & 22 \\
\hline Fungating growth & 53 & 11 \\
\hline Polyp & 12 & 3 \\
\hline
\end{tabular}

Table 2: Biopsy sites in upper GIT.

\begin{tabular}{|c|c|c|}
\hline Site & No of cases & Percentage \\
\hline Oesophagus & 33 & 7 \\
\hline Oesophagogastric junction & 6 & 1 \\
\hline Stomach & 379 & 84 \\
\hline Duodenum & 36 & 8 \\
\hline
\end{tabular}


Table 3:Non-neoplastic lesions of upper GIT.

\begin{tabular}{|l|c|c|}
\hline \multicolumn{2}{|c|}{ NON-NEOPLASTIC LESIONS } & NO OF CASES \\
\hline \multirow{3}{*}{ INFECTIVE } & Oesophageal candidiasis & 94 \\
\cline { 2 - 3 } & H.pyloric gastritis & 10 \\
\hline \multirow{3}{*}{ INFLAMMATORY } & Chronic oesophagitis & 1 \\
\cline { 2 - 3 } & Barrett's oesophagus & 1 \\
\cline { 2 - 3 } & Atrophic gastritis & 237 \\
\cline { 2 - 3 } & Chronic gastritis & 4 \\
\cline { 2 - 3 } & Inflammatory polyp & 31 \\
\cline { 2 - 3 }
\end{tabular}

Table 4: Neoplastic lesions of upper GIT.

\begin{tabular}{|l|c|c|}
\hline \multicolumn{2}{|c|}{ NEOPLASTIC LESIONS } & NO OF CASES \\
\hline \multirow{3}{*}{ BENIGN } & Hyperplastic polyp & 1 \\
\cline { 2 - 3 } & Gastric adenoma & 2 \\
\cline { 2 - 3 } & Carcinoid tumour & 44 \\
\hline \multirow{3}{*}{ MALIGNANT } & Adenocarcinoma & 23 \\
\cline { 2 - 3 } & Squamous cell carcinoma & 1 \\
\cline { 2 - 3 } & Neuroendocrine tumour & 1 \\
\cline { 2 - 3 } & Intramucosal carcinoma & 1 \\
\cline { 2 - 3 } & Gastrointestinal amyloid & \\
\cline { 2 - 3 } & & \\
\hline
\end{tabular}

Table 5: Clinicopathological correlation.

\begin{tabular}{|c|c|c|}
\hline Clinico-histopathological correlation & Frequency & Percentage \\
\hline No correlation & 88 & $20 \%$ \\
\hline Correlation & 366 & $80 \%$ \\
\hline Total & 454 & $\%$ \\
\hline
\end{tabular}

Table 6: Clinico-pathological correlation of neoplastic lesions of upper GIT.

\begin{tabular}{|c|c|c|c|c|}
\hline \multirow{2}{*}{} & \multicolumn{4}{|c|}{ Neoplastic lesions } \\
\cline { 2 - 5 } & \multicolumn{2}{|c|}{ Benign } & 35 & \multicolumn{2}{c|}{ Malignant } \\
\hline Non Correlating & 5 & $100 \%$ & 35 & $50 \%$ \\
\hline Correlating & 0 & $0 \%$ & $50 \%$ \\
\hline
\end{tabular}

Table 7: Clinico-pathological correlation of non-neoplastic lesions of upper GIT.

\begin{tabular}{|c|c|c|c|c|}
\hline \multirow{2}{*}{} & \multicolumn{3}{|c|}{ Non-neoplastic lesions } \\
\cline { 2 - 5 } & \multicolumn{2}{|c|}{ Inflammatory } & 2 & $2 \%$ \\
\hline Non Correlating & 46 & $16 \%$ & 93 & $98 \%$ \\
\hline Correlating & 238 & $84 \%$ & 93 Infective \\
\hline
\end{tabular}




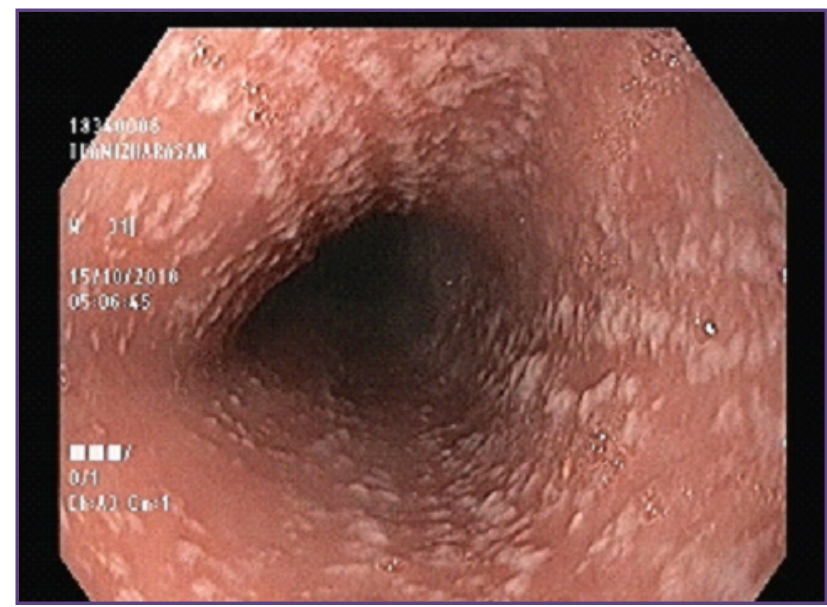

Fig. 1: Endoscopic picture of oesophageal candidiasis showing numerous scattered curdy white precipitates throughout the oesophagus.

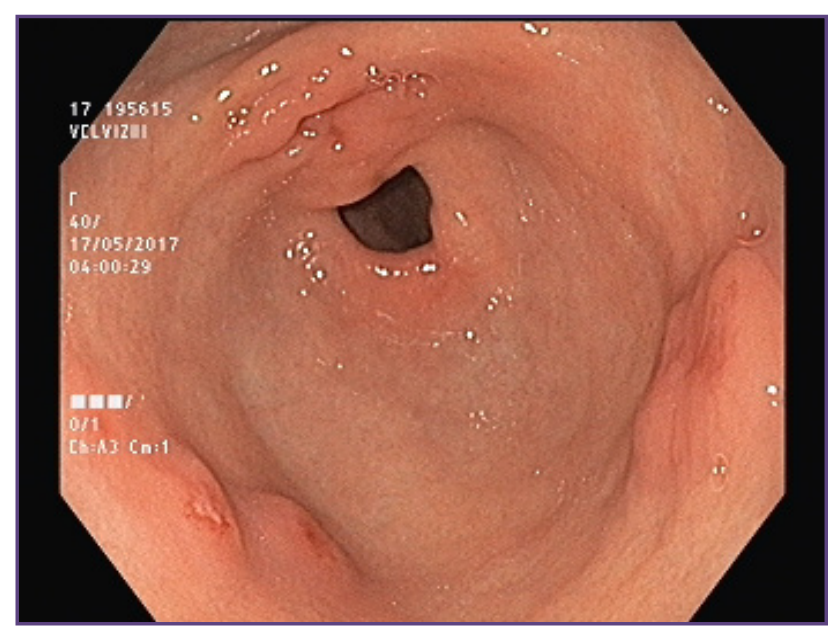

Fig. 3: Endoscopic picture of stomach showing two nodular lesions with surface ulceration.

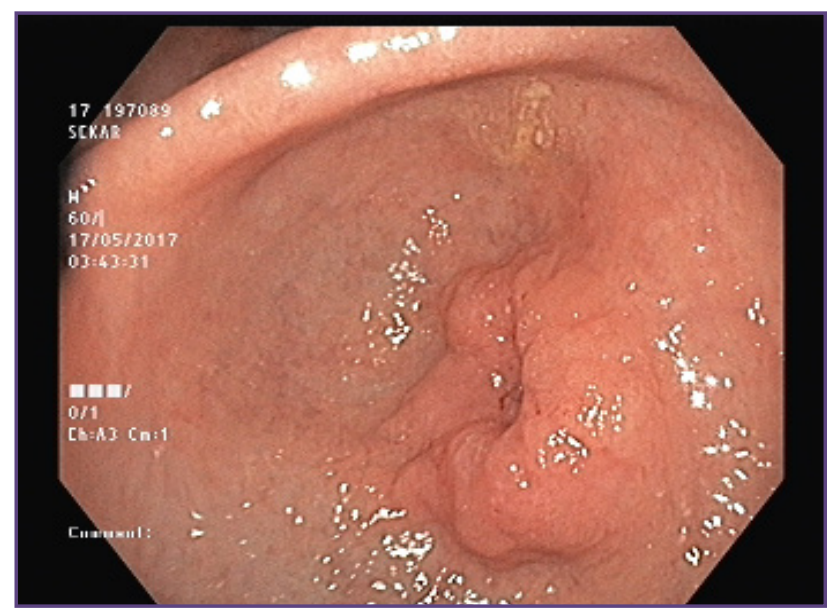

Fig.0 5: Endoscopic picture of antrum of stomach showing a circumferential growth.

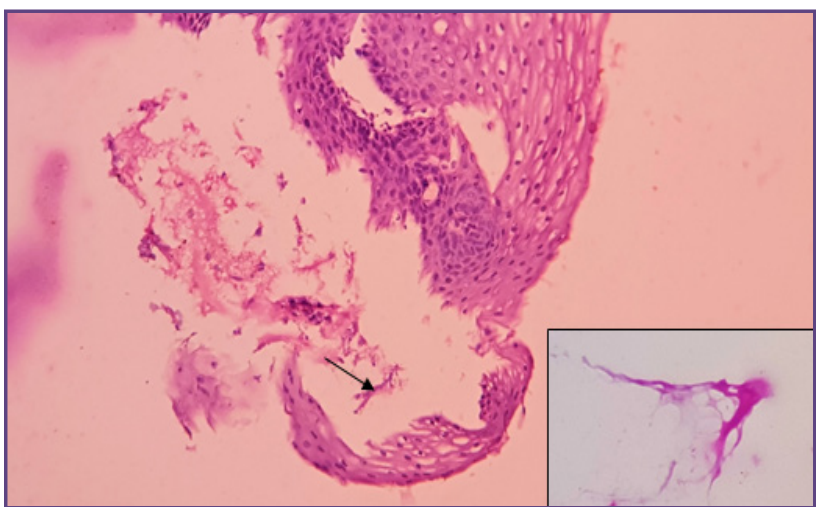

Fig. 2: Microscopic picture of Oesophageal candidiasis showing fungal hyphae and budding forms (arrow head) along with strips of stratified squamous epithelium (H \& E, 40X). Insert microscopic picture shows PAS positive fungal hyphae (PAS, 400X)

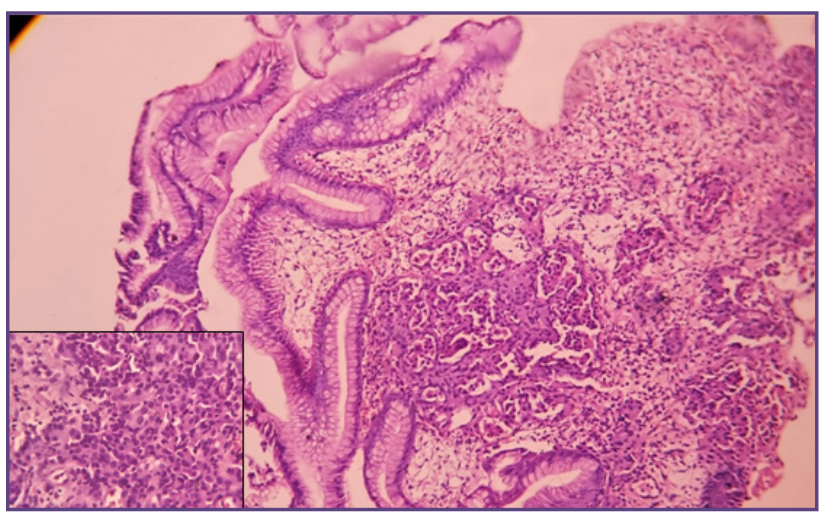

Fig. 4: Microscopic picture of the nodular lesion in endoscopy shows Carcinoid tumour with tumour cells arranged in nests (H \& E, 10X). Insert picture shows tumour cells arranged in nests and composed of bland uniform neoplastic cell and thin blood vessels. (H\&E, 40X)

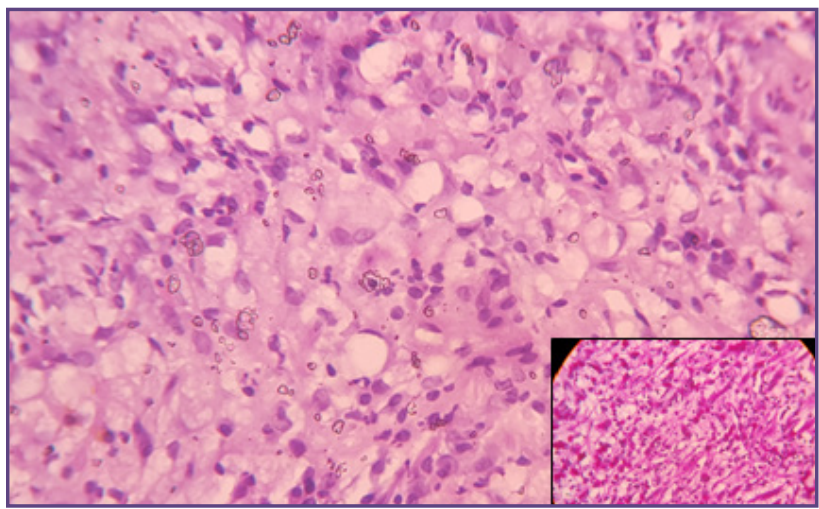

Figure 6: Microscopic picture of growth form the antrum of the stomach showing Signet ring cell adenocarcinoma characterised by the presence of numerus signet ring cells (H \& E, 100X). Insert pic shows PAS positivity of intracellular mucin (PAS, 100x) 


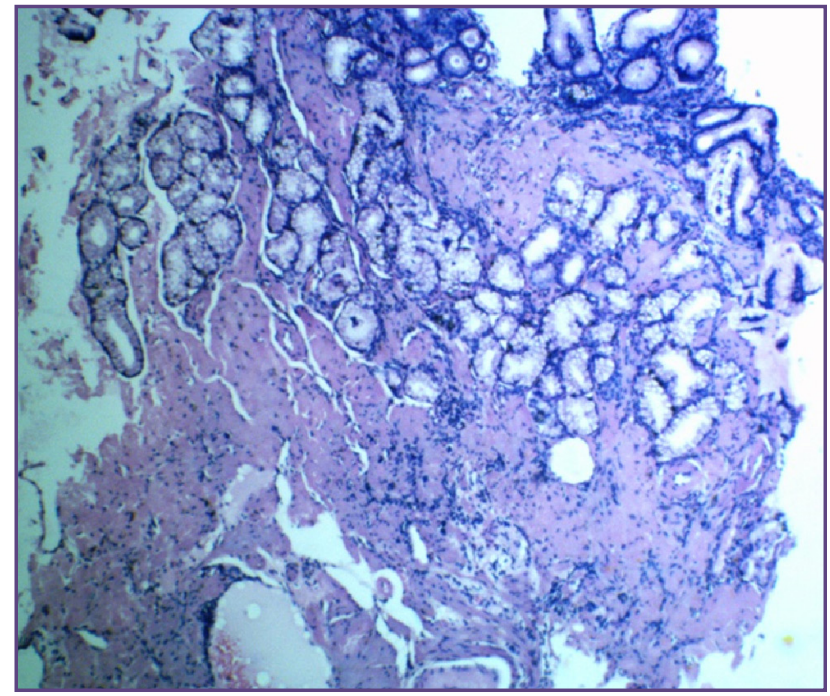

Fig. 7: Microscopic picture of inflamed mucosa from the gastric antrum showing gastrointestinal amyloidosis. Extracellular homogenous eosinophilic deposits of amyloid replacing the lamina propria seen. (H\&E, 10X).

\section{Discussion}

The study was conducted in the Department of Pathology in Mahatma Gandhi Medical College and Research Institute, Puducherry, Sri Balaji Vidyapeeth Deemed to be University during the period of December 2016 to May 2018. The study includes endoscopic biopsies from upper gastrointestinal tract along with correlation of age, sex, clinical symptoms, endoscopic findings and histopathological diagnosis.

Comparision with Gender: Gastric lesions are generally more common among males worldwide. The findings of the present study showed male predominance with male : female ratio of 1.17:1 and they are similar to the study of Rashmi et $\mathrm{al}^{[3]}$, Islam et $\mathrm{al}^{[5]}$,Hussain et $\mathrm{al}^{[6]}$, $\mathrm{K}$ et $\mathrm{al}^{\left[{ }^{[7]}\right.}$,Somani et $\mathrm{al}^{[9]}$, Khandelia et $\mathrm{al}^{[10]}$ and Rani et all ${ }^{[11]}$. Increased exposure to risk factors and large number of male patients attending the hospital can explain the gender ratio.

Age Distribution: Out of the 454 cases studied, majority of gastrointestinal lesion occurs in individuals in their $4^{\text {th }}$ decade of life (22.5\%). The similar studies by Rashmi et $\mathrm{al}^{[3]}$, Hussain et $\mathrm{al}^{[6]}$, $\mathrm{K}$ et al ${ }^{[7]}$ and Khandelia et al ${ }^{[10]}$ are showed the highest age incidence in the age group of 41$50 y r s$. However in the study by Islam et $\mathrm{al}^{[5]}$ Somani et al ${ }^{[9]}$ and Rani et $\mathrm{al}^{[11]}$ the most sampled age group were in the $6^{\text {th }}$ decade. This difference could be due to geographical variation and in the exposure to risk factors including dietary habits, lifestyle and environmental factors.

Clinical Manifestations in Upper Git Lesions: Dysphagia and dyspepsia remains as the most common

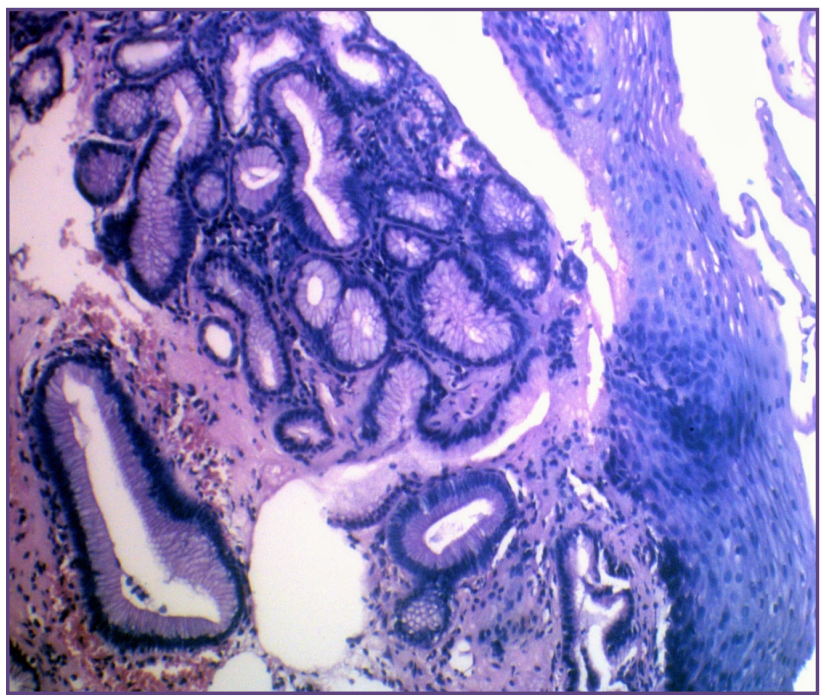

Fig. 8: Microscopic picture of Barretts oesophagus showing columnar metaplasia with strips of stratified squamous epithelium (H \& E, 10X).

non-specific clinical complaint of upper gastrointestinal lesions followed by epigastric pain and vomiting. These findings are similar to the studied done by of Islam et $\mathrm{al}^{[5]}$, Hussain et $\mathrm{al}^{[6]}, \mathrm{K}$ et $\mathrm{al}^{[7]}$ and Khandelia et $\mathrm{al}^{[10]}$.The most common clinical manifestation of inflammatory disorder remains to be dysphagia and dyspepsia similar to the study of Hussain et $\mathrm{al}^{[6]}$ and $\mathrm{K}$ et $\mathrm{al}^{\left[{ }^{7]}\right.}$. In malignant lesions, along with dysphagia, the frequency of loss of appetite and weight loss were prevalent.

Distribution of Lesions: In the present study, stomach was the most commonly sampled site constituting $83.4 \%$ of the all the upper endoscopic biopsy sites. The studies conducted by Rashmi et al ${ }^{[3]}$, Islam et $\mathrm{al}^{[5]}$, Hussain et $\mathrm{al}^{[6]}$, $\mathrm{K}$ et $\mathrm{al}^{[7]}$, Somani et $\mathrm{al}^{[9]}$ and Rani et all[11] also showed similar findings. The second and third most common site of biopsy was duodenum and oesophagus constituting $8 \%$ and $7.3 \%$ respectively. These findings are similar to the study by $\mathrm{K}$ et $\mathrm{al}^{[7]}$.

Lesions of Oesophagus: Squamous cell carcinoma remains the most common malignant lesion of the oesophagus comprising about $57.7 \%$ in the present study. Studies conducted by Islam et $\mathrm{al}^{[5]}, \mathrm{K}$ et $\mathrm{al}^{[7]}$, Khandelia et $\mathrm{al}^{[10]}$ and Rani et all ${ }^{[11]}$ also showed similar finding of squamous cell carcinoma as the predominant neoplastic lesion of oesophagus. Two cases of adenocarcinoma of oesophagus were reported in our study. The most common non-neoplastic lesion in our study was oesophagitis accounting for about $30.3 \%$. Similar findings were reported by Islam et $\mathrm{al}^{[5]}$ and $\mathrm{K}$ et $\mathrm{al}^{[7]}$. One case of Barretts oesophagus and oesophagal candidiasis were reported 
in our study. No benign lesions of oesophagus were encountered during our study period.

Lesions of Og Junction: In the present study, only malignant lesions were encountered in the oesophagogastric junction with the majority being squamous cell carcinoma constituting $66.6 \%$ followed by adenocarcinoma constituting $33.3 \%$. In the study conducted by $\mathrm{K}$ et a ${ }^{[7]}$, inflammatory lesions such as chronic gastritis and reflux gastritis were predominant comprising of about $80 \%$ of the lesion of OG junction followed by meagre $20 \%$ of neoplastic lesions. In the study by Sheikh et $\mathrm{al}^{[8]}$ adenocarcinoma was the most predominant lesion of the OG junction. This variation in the nature of the predominant lesion can be attributed to smaller sample size of both Sheikh et a ${ }^{[8]}$ and $\mathrm{K}$ et $\mathrm{al}^{[7]}$ studies.

Lesions of Stomach: In our study, among the 379 samples from the stomach the commonest lesion was chronic gastritis $(62.5 \%)$ followed by H.pyloric gastritis (24.8\%). Study conducted by $\mathrm{K}$ et al ${ }^{[7]}$ on 61 gastric biopsies and Khandelia et $\mathrm{al}^{[10]}$ on 40 gastric biopsies also showed similar findings. In our study, malignant lesions accounted for $11.1 \%$ of the gastric lesions and similar findings were reported in the studies by Isalm et $\mathrm{al}^{[5]}, \mathrm{K}$ et a ${ }^{[7]}$ and Sheikh et $\mathrm{al}^{[8]}$.

One case of gastrointestinal amyloidosis and intramucosal carcinoma were reported in our study each accounting for about $0.3 \%$ of the gastric lesions.

The study of Isalm et a ${ }^{[5]}$ and Sheikh et a ${ }^{[8]}$ showed higher incidence of H.pylori infection compared to the present study of $24.8 \%$. Treatment for H.pylori infection given prior to biopsy sampling could be the reason for reduced cases of H.pylori positive samples.

Lesions of Duodenum: In the present study, out of 36 samples from the duodenum, the most commonly encountered inflammatory lesion is chronic duodenitis (86\%). Similar findings were observed in the study conducted by $\mathrm{K}$ et $\mathrm{al}^{\left[{ }^{[7]}\right.}$ and Rani et $\mathrm{al}^{[11]}$. In the study conducted by Islam et al ${ }^{[5]}$, hyperplastic polyp was the commonest lesion accounting for about $73 \%$ of the 15 samples from duodenum whereas in our study, only 2 polypoidal lesions were reported accounting for $5 \%$ of the 36 samples. The smaller sample size of Islam et $\mathrm{al}^{\left[{ }^{[5]}\right]}$ and $\mathrm{K}$ et $\mathrm{al}^{[7]}$ along with geographic and dietary variation could the reason for non-concordance of their results with our study. One case of adenocarcinoma of duodenum was reported in the present study but the surgically resected specimen from the same patient revealed peri-ampullary carcinoma infiltrating the duodenal wall. This reinforces the need for complete clinical evaluation, proper sampling of the suspicious area along with radiological image findings for an accurate histopathological report.

Clinicopathological Concordance: In the present study, Clinicopathological concordance was observed in $84 \%$ of cases. The study of Rashmi et al ${ }^{[3]}$ and Somani et al ${ }^{[9]}$ showed $78 \%$ and $91 \%$ concordance respectively. Their smaller sample size of 100 could be reason for this variation.

\section{Conclusion}

Histopathological evaluation is the gold standard for diagnosis of GIT lesions and the accompanying clinical data along with endoscopic findings aids in proper diagnosis and management of the patient. The correlation of these 2 parameters greatly supports the detection of lesions even in unsuspected cases.

\section{Acknowledgements}

Authors acknowledge the immense help received from the scholars whose articles are cited and included in references of this manuscript. The authors are also grateful to authors / editors / publishers of all those articles, journals and books from where the literature for this article has been reviewed and discussed.

\section{Reference}

1. Rosai J, Chapter 11. Gastrointestinal tract. Rosai and Ackerman's Surgical Pathology 10th edition.

2. Kumar V, Abbas AK, Fauston. Robbins and Cotran Pathologic Basis of disease. Chapter 17. Gastrointestinal tract 9th Edition

3. Rashmi K, Karar A, Mangala G. A study on histopathological spectrum of upper gastrointestinal tract endoscopic biopsies. Int J Med Res Health Sci. 2013;2(3):418-24

4. Suvarna KS, Layton C, Bancroft JD, editors. Theory and practice of histological techniques. 7. ed. Edinburgh: Elsevier Churchill Livingston; 2013. 637 p.

5. Islam SMJ, Ahmed ASMM, Ahmad MSU, Hafiz S. Endoscopic and Histologic Diagnosis of Upper Gastrointestinal Lesions, Experience in a Port City of Bangladesh. Chattagram Maa-O-Shishu Hospital Medical College Journal. 2014 Nov 28;13(3):11-4.

6. Hussain SI, Reshi R, Akhter G, Beigh A clinico histopathological study of upper gastrointestinal tract endoscopic biopsies. International Journal of Current Research and Review. 2015;7(16):78-85.

7. Shanmugasamy K, Bhavani K, Anandraj VK, Narasimhan R, Kotasthane DS. Clinical Correlation of Upper Gastrointestinal Endoscopic Biopsies with Histopathological Findings and To Study the Histopathological Profile of Various Neoplastic and Non-Neoplastic Lesions. J Pharm Biomed Sci 2016;06(03):220-224 
8. Sheikh BA, Hamdani SM, Malik R. Hisotopatholgic spectrum of lesions of upper gastrointestinal tract - A study of endoscopic biopsies. Glob J Med Public Heal. 2015;4(4):1-8

9. Somani N, Patil P. Histopathological study of the upper gastrointestinal tract endoscopic biopsies. Annals of Pathology and Laboratory Medicine 2018;5(8):683-8.

10. Khandelia R, Saikia M. Histopathological spectrum of upper gastrointestinal tract mucosal biopsies: A Prospective study. International Journal of Medical Science and Clinical Inventions 2017;4(11):3314-16

11. Rani D, Bhuvan S, Gupta A. A study of morphological spectrum of upper gastrointestinal tract lesions by endoscopy and correlation between endoscopic and histopathological findings. Indian J Pathol Oncol 2019;6(1):28-34.

*Corresponding author:

Dr. Bhavani K, Mahatma Gandhi Medical College and Research Institute, Pondicherry Cuddalore EC Road, Pillayarkuppam, Puducherry, India - 607402 .

Phone: +918220201448

Email: drbhavanipatho@gmail.com

Financial or other Competing Interests: None. 